\title{
THE EVOLUTIONARY GENETICS AND DEVELOPMENTAL BASIS OF WING PATTERN VARIATION IN THE BUTTERFLY BICYCLUS ANYNANA
}

\author{
Antonia F. MONTEIRo, ${ }^{1}$ PAUl M. Brakefield,${ }^{1}$ AND Vernon French ${ }^{2}$ \\ ${ }^{1}$ Section of Evolutionary Biology, Institute of Evolutionary and Ecological Sciences, \\ University of Leiden, Schelpenkade 14a, $2313 \mathrm{ZT}$ Leiden, The Netherlands \\ ${ }^{2}$ Institute of Cell, Animal and Population Biology, University of Edinburgh, \\ Kings Buildings, West Mains Road, Edinburgh EH9 3JT, UK
}

\begin{abstract}
We have studied interactions between developmental processes and genetic variation for the eyespot color pattern on the adult dorsal forewing of the nymphalid butterfly, Bicyclus anynana. Truncation selection was applied in both an upward and a downward direction to the size of a single eyespot consisting of rings with wing scales of differing color pigments. High heritabilities resulted in rapid responses to selection yielding divergent lines with very large or very small eyespots. Strong correlated responses occurred in most of the other eyespots on each wing surface. The cells at the center of a presumptive eyespot (the "focus") act in the early pupal stage to establish the adult wing pattern. The developmental fate of the scale cells within an eyespot is specified by the "signaling" properties of the focus and the "response" thresholds of the epidermis. The individual eyespots can be envisaged as developmental homologues. Grafting experiments performed with the eyespot foci of the selected lines showed that additive genetic variance exists for both the response and, in particular, the signaling components of the developmental system. The results are discussed in the context of how constraints on the evolution of this wing pattern may be related to the developmental organization.
\end{abstract}

Key words. - Bicyclus anynana, butterfly wing, constraint, development, eyespot, genetic correlation, gradient, pattern formation, quantitative genetics, selection.

Received January 13, 1993. Accepted September 8, 1993.

Studies of the evolutionary genetics of variation in form within natural populations seldom consider the developmental mechanisms involved in the translation of genotype to phenotype. This is, however, necessary for a complete understanding of evolutionary change and the constraints upon it (see Scharloo 1987, 1990). Variation in the wing color pattern of particular species of Lepidoptera has provided the material for numerous studies of genetic variation, natural selection, and adaptation (examples in Brakefield 1984, 1987a; Turner 1984; Bowers et al. 1985; Mallet and Barton 1989; Watt et al. 1989; Kingsolver and Wiernasz 1991a, 1991b). In addition, this system has great potential for the experimental investigation of the processes of pattern determination underlying the development of the phenotype (Nijhout, 1991). Surgical manipulations can reveal the cell interactions by which the pattern of cell fate is specified, and the biochemical and physiological processes involved in the synthesis of the color pigments can be examined (Nijhout 1980, 1991; Koch 1992). Furthermore, mathematical modeling has yielded insights into the developmental basis of the extreme diversity in wing pattern that is ob- served across species of Lepidoptera (Nijhout 1990).

We are studying the evolutionary genetics of variation in the pattern of submarginal eyespots on the wings of the African butterfly Bicyclus anynana (Nymphalidae, Satyrinae). Each eyespot is a set of concentric rings of different colors formed by wing scales containing different pigments. A "prototype" for the species-rich genus Bicyclus exhibits eyespots centered within each of the marginal wing cells (Schwanwitsch 1924; Condamin 1973). Bicyclus anynana, in common with many other species of satyrine, expresses phenotypic plasticity in the eyespots on the ventral surface of the wings (Brakefield and Reitsma 1991). Butterflies flying in the wet season exhibit conspicuous, well-developed ventral eyespots, whereas these eyespots are dramatically reduced in size in the dry season adults. A functional explanation has been developed (Brakefield and Larsen 1984; Brakefield 1987b) in terms of seasonal changes in the way in which selection favors crypsis (no eyespots) or devices to deflect predator attacks away from the vulnerable body. Both rearing temperature and larval development time are important in determining the ven- 
tral eyespot phenotype (Brakefield and Reitsma 1991; Windig 1992). In addition, substantial additive genetic variation exists for ventral eyespot size (Holloway et al. 1993; Windig 1994). Bicyclus anynana also exhibits one large and one small eyespot on the dorsal surface of the forewing. These are not exposed at rest and express little phenotypic plasticity (J. C. Roskam unpubl. data).

French and Brakefield $(1992,1995)$ and Brakefield and French (1995) have used surgical techniques to investigate the developmental mechanisms by which eyespots are specified on the dorsal forewing of $B$. anynana. The group of cells at the center of a presumptive eyespot (the focus) acts in the early pupal stage to establish the normal pattern of the eyespot (Nijhout 1980). Hence, grafting a focus to a different position causes an ectopic eyespot to form around it (Brakefield and French 1993; French and Brakefield 1995), and early damage to a focus eliminates or greatly diminishes the corresponding adult eyespot (French and Brakefield 1992). However, damage at a slightly later stage can mimic the action of a focus; thus, a focal injury can increase the size of the small forewing eyespot, and an injury elsewhere can provoke formation of an ectopic eyespot. These surgical experiments show that cell fate (and hence the color pattern that appears in the late pupae) is specified by the "signaling" properties of the foci and the "response" thresholds of the epidermis (Nijhout 1980, 1991).

Interactions between developmental processes and genetic variation are explored in this study of wing pattern in B. anynana. Selection experiments are used to estimate genetic variances for the size of the large eyespot on the dorsal forewing. Surgical experiments were then performed on the divergent lines produced by the selection to investigate whether the response to selection involved both the signaling and response components of the developmental process that specifies adult phenotype. Correlated responses to selection in other eyespots are also examined. The results are discussed in the context of how constraints on the evolution of this wing pattern may be related to the developmental organization.

\section{MATERIALS AND METHODS}

\section{Experimental Animals}

All butterflies were of the wet season form and were reared at $28^{\circ} \mathrm{C}(12 \mathrm{D}: 12 \mathrm{~L} ; 80 \%-90 \% \mathrm{RH})$ from a laboratory stock established about 3 years earlier from about 80 gravid females from Nkhata Bay in Malawi. The stock had been maintained at an adult population size of at least 500 individuals. Larvae were reared on young maize plants and adults fed on mashed banana (further details in Holloway et al. 1993).

\section{Selection on Eyespot Size}

In each generation, butterflies were selected on the basis of the total diameter of the large dorsal posterior forewing eyespot relative to the forewing length (fig. 1). This ratio is uncorrelated with wing size within each sex. Other characters were also measured to monitor correlated responses in the size or number of certain other eyespots on the forewing and the hindwing (fig. 1).

A HIGH and a LOW line were selected over five generations, starting from a single large population reared from the stock. Measurements were made, using a micrometer eyepiece in a binocular microscope, on both males and females, which were then numbered individually. Conservative estimations of the threshold values for selection were made early in the period of adult emergence (an average of 320 adults of each sex emerged in each line per generation), such that final totals of approximately 100 males and 100 females could be mixed in a mating cage as emergence proceeded. After mating, only 40 of the most extreme surviving females were allowed to lay eggs to produce the next generation. This procedure maximized successful mating and the number of surviving selected females, although it resulted in slightly stronger selection on females than on males.

Offspring-parent regression was used to estimate heritability of the size of the selected eyespot (relative to wing length) in the unselected stock by rearing 18 families (minimum of five offspring of each sex) derived from mating pairs collected from the stock and kept in the same controlled conditions. Estimates of realized heritability were made by linear regression of the response to selection in the selection lines (see Falconer 1989).

\section{Grafting Experiments}

The focus of the selected posterior eyespot was moved to a more anterior position on a host wing. Operations were performed on the left wings of pupae reared from the selected lines after the fifth generation, using donor and host animals 


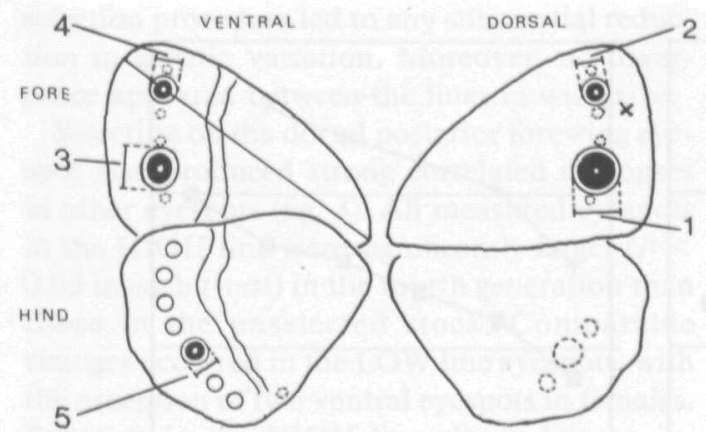

FIG. 1. Wing eyespot pattern of Bicyclus anynana. Bars indicate the measurements made on five eyespots. Dorsal forewing: 1, posterior spot and 2, anterior spot; ventral forewing: 3 , posterior spot and 4, anterior spot; 5 , ventral fifth hindwing spot. Dotted circles show the position of additional eyespots that were counted when present. The solid line on the ventral forewing indicates wing length; this measurement was made using a different magnification. The cross indicates the position used for the nonfocal damage experiments.

matched as far as possible in size and pupation time. At 3-4 h after pupation, a square of cuticle plus epidermis was cut from the donor and grafted into a prepared site on the host pupal wing (French and Brakefield in prep). The grafted tissue was about one-third the width of the donor wing cell. Reciprocal grafts were performed between pupae from the same selected line (controls, to assess the effect of focal grafting on the size of the resulting eyespot) and between pupae from the HIGH and LOW lines (to assess the contributions of the focal signal and epidermal response). Wing length and the diameters of the control (right) and induced eyespots were measured after adult emergence. For analysis, all eyespot diameters were converted into areas by assuming that each eyespot was a perfect circle. Nonparametric statistics were used to analyze the data because of some skewness in distributions.

\section{Damage Experiments}

Small regions of dorsal forewing epidermis were killed at the presumptive centers (the foci) of the selected posterior eyespot and the anterior (small) eyespot, and at a nonfocal site (see fig. 1). Operations were performed on pupae reared from the selected lines after the fifth generation, using an unheated tungsten needle ("sham cautery"see French and Brakefield 1992). Samples of about 25 pupae from each line were treated at 1 , $6,12,18,24$, and $30 \mathrm{~h}$ after pupation to cover

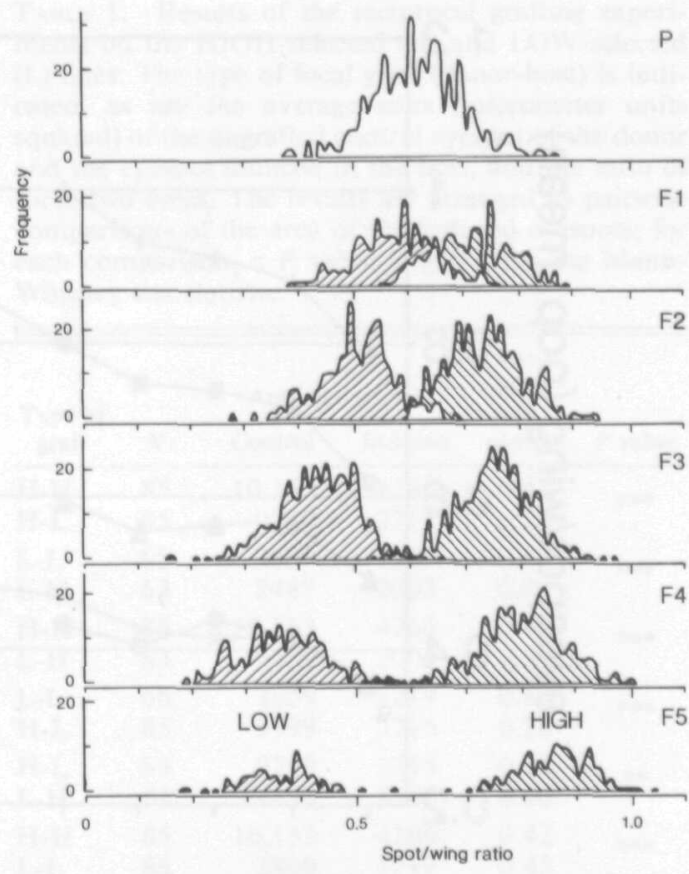

FIG. 2. Frequency distributions of the size of the selected eyespot relative to wing length for male butterflies of the HIGH and the LOW lines in the course of the selection experiment. Overlapping areas of the distributions are unhatched.

the whole period during which pattern determination occurs at $28^{\circ} \mathrm{C}$ (French and Brakefield 1992). After adult emergence, wing lengths, eyespot diameters, and ectopic pattern elements were measured on the control (right) and experimental wings.

\section{RESULTS \\ Genetics of Eyespot Size}

A rapid response to selection occurred in both the HIGH and LOW lines, leading to almost nonoverlapping frequency distributions after five generations for eyespot size (relative to wing size; fig. 2 for males; females showed the same pattern). Estimates of realized heritability in males are $0.54(\mathrm{SE}=0.06)$ and $0.67( \pm 0.06)$ for the HIGH and LOW lines, respectively. The corresponding estimates for females are $0.47( \pm 0.03)$ and $0.50( \pm 0.05)$. These are comparable to the value of $0.76( \pm 0.23)$ obtained by regression of midoffspring on midparent values and confirm that substantial additive genetic variation for the size of the main dorsal eyespot exists in our stock of Bicyclus anynana. No evidence exists that the 


\section{A) HL: males}

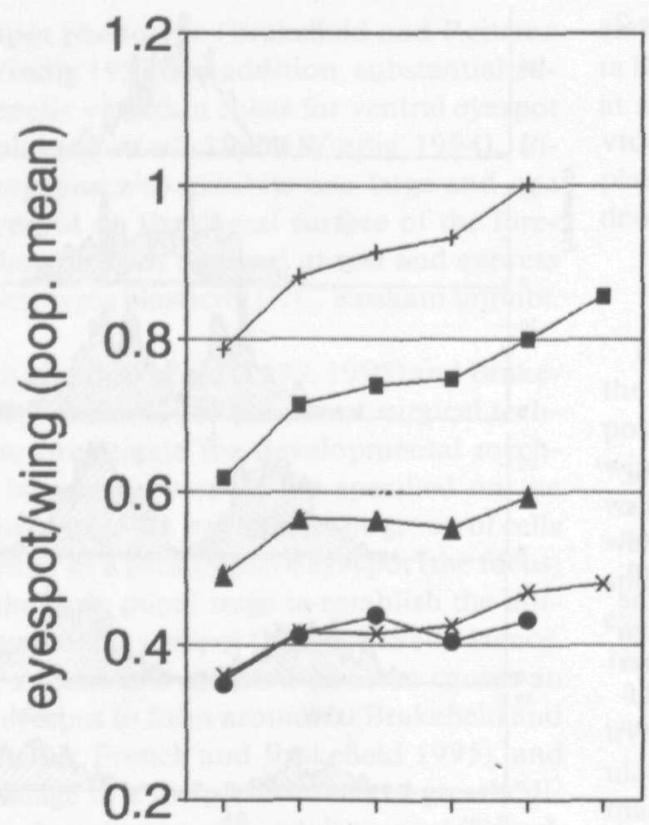

B) LL: males

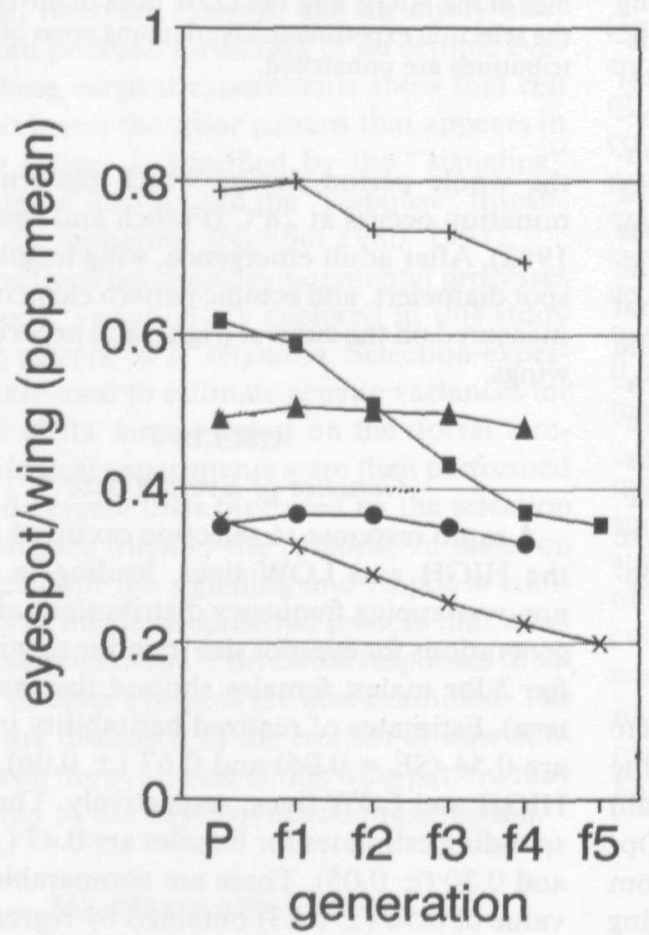

females

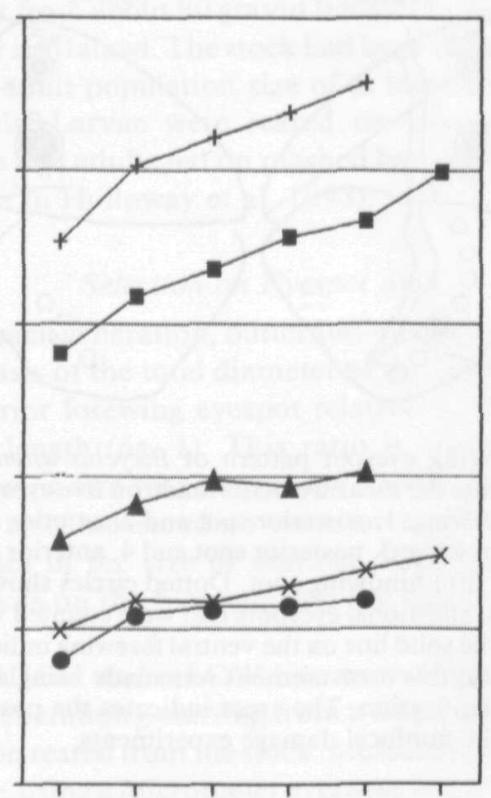

females

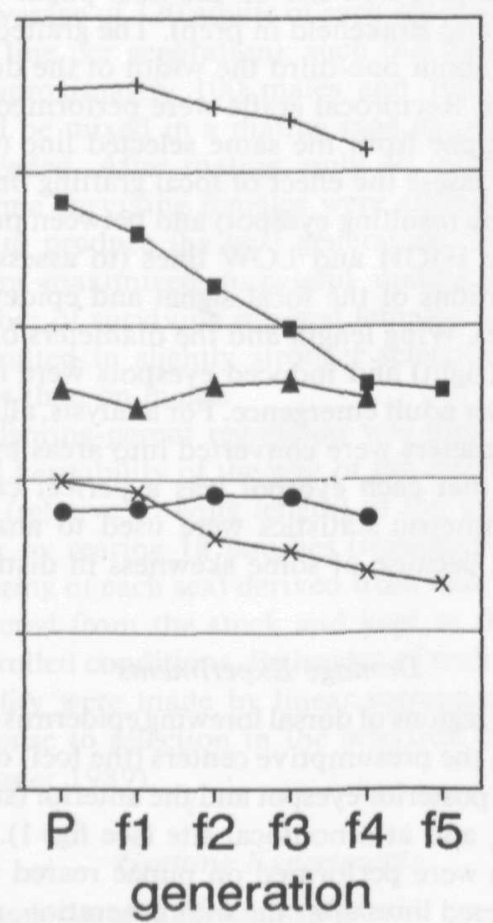

FIG. 3. Responses to selection (HL, HIGH line; LL, LOW line) for the selected eyespot (character 1, solid square; fig. 1). The correlated responses for other eyespot characters are also shown (character 2, $\mathrm{x}$; character $3,+$; character 4 , solid circle; character 5 , solid triangle). All eyespot sizes are relative to wing length. 
selection procedure led to any substantial reduction in genetic variation. Moreover, no divergence appeared between the lines in wing size.

Selection on the dorsal posterior forewing eyespot also produced strong correlated responses in other eyespots (fig. 3). All measured eyespots in the HIGH line were significantly larger $(P<$ 0.05 in each $t$-test) in the fourth generation than those in the unselected stock. Comparable changes occurred in the LOW line eyespots, with the exception of two ventral eyespots in females. Selection in the HIGH line also led to an increase, on all wing surfaces, in the frequency of small additional eyespots in other wing cells (comparison of parental and fifth selected generations by $t$-test: $P<0.05$ in each case, except for the forewing ventral surface in males).

\section{Eyespots Formed around Grafted Foci}

To investigate the effects of selection on the mechanism of eyespot development, reciprocal grafts were made between pairs of pupae taken from the same or from different selected lines. Four types of graft were made: HIGH line focus grafted into a HIGH line wing; LOW line focus into LOW line wing; HIGH line focus into LOW line wing; and LOW line focus grafted into HIGH line wing. About 100 grafts of each type were performed and, of these, the great majority were successful and induced the formation of a measurable eyespot (fig. 4).

The results of the different types of graft were analyzed (table 1), considering the area of an induced eyespot, and also its area relative to that of the control eyespot (on the contralateral wing of the donor animal). Several conclusions can be drawn:

(1) In both the HIGH and LOW lines, the average effect of the grafting operation is to reduce eyespot area to about $40 \%$ of the control.

(2) HIGH and LOW line foci differ in their effect. The eyespot resulting from a HIGH line focus grafted into either a HIGH or LOW line host has over twice the area of that resulting from the graft of a LOW line focus to the corresponding host (see fig. 4).

(3) The host HIGH or LOW line environment influences eyespot size. Either type of focus, when grafted into a HIGH line host, produces a larger eyespot than when grafted into a LOW line host (50\% larger for a HIGH line and $86 \%$ larger for a LOW line focus). Thus, in a HIGH line host, the HIGH line focus produces an eyespot only $42 \%$ of control size, whereas a LOW line focus
TABLE 1. Results of the reciprocal grafting experiments on the HIGH-selected $(\mathrm{H})$ and LOW-selected (L) lines. The type of focal graft (donor-host) is indicated, as are the average sizes (micrometer units squared) of the ungrafted control eyespot of the donor and the eyespot induced in the host, and the ratio of these two areas. The results are arranged as pairwise comparisons of the area of the induced eyespots; for each comparison, a $P$ value is given for the MannWhitney test statistic.

\begin{tabular}{|c|c|c|c|c|c|}
\hline \multirow{2}{*}{$\begin{array}{c}\text { Type of } \\
\text { graft }\end{array}$} & \multirow[b]{2}{*}{$N$} & \multicolumn{2}{|c|}{ Area of eyespot } & \multirow{2}{*}{$\begin{array}{l}\text { Ratio } \\
\text { of in- } \\
\text { duced : } \\
\text { control }\end{array}$} & \multirow[b]{2}{*}{$P$ value } \\
\hline & & Control & Induced & & \\
\hline $\mathrm{H}-\mathrm{H}$ & 85 & 10,153 & 4266 & 0.42 & \multirow{2}{*}{ *** } \\
\hline H-L & 85 & 9799 & 2715 & 0.28 & \\
\hline $\mathbf{L}-\mathbf{L}$ & 68 & 2809 & 1219 & 0.43 & \multirow{2}{*}{ *** } \\
\hline L-H & 63 & 2489 & 2003 & 0.80 & \\
\hline H-H & 85 & 10,153 & 4266 & 0.42 & \multirow{2}{*}{$* * *$} \\
\hline L-H & 63 & 2489 & 2003 & 0.80 & \\
\hline L-L & 68 & 2809 & 1219 & 0.43 & \multirow{2}{*}{ **** } \\
\hline H-L & 85 & 9799 & 2715 & 0.28 & \\
\hline H-L & 85 & 9799 & 2715 & 0.28 & \multirow{2}{*}{ ** } \\
\hline L-H & 63 & 2489 & 2003 & 0.80 & \\
\hline $\mathrm{H}-\mathrm{H}$ & 85 & 10,153 & 4266 & 0.42 & \multirow[t]{2}{*}{ **** } \\
\hline L-L & 68 & 2809 & 1219 & 0.43 & \\
\hline
\end{tabular}

** $P<0.01 ;{ }^{* * *} P<0.001$.

induces an eyespot $80 \%$ of the size of the control on the donor animal.

(4) Although the nature of both the focus and the surrounding epidermis influences eyespot size, the focus has the stronger effect. Hence, a HIGH line focus grafted into a LOW line host gives an eyespot that is $36 \%$ larger on average than that resulting from a LOW line focus in a HIGH line host.

The focal grafting experiments demonstrate that selection has produced a difference between HIGH and LOW lines in eyespot size that is mediated by changes in both the activity of the focus and the response of the wing epidermis. These changes were further investigated by damaging small regions of wing epidermis at focal and nonfocal sites.

\section{Focal Damage}

Damage to the foci of the large posterior and small anterior dorsal eyespots produced results (fig. 5) very similar to those obtained previously using the unselected stock (French and Brakefield 1992). Early injury ( $1 \mathrm{~h}$ and $6 \mathrm{~h}$ after pupation) removed (especially in the LOW line) or reduced the eyespots relative to controls. Later at $12 \mathrm{~h}$ and $18 \mathrm{~h}$, small reductions (especially in the pos- 


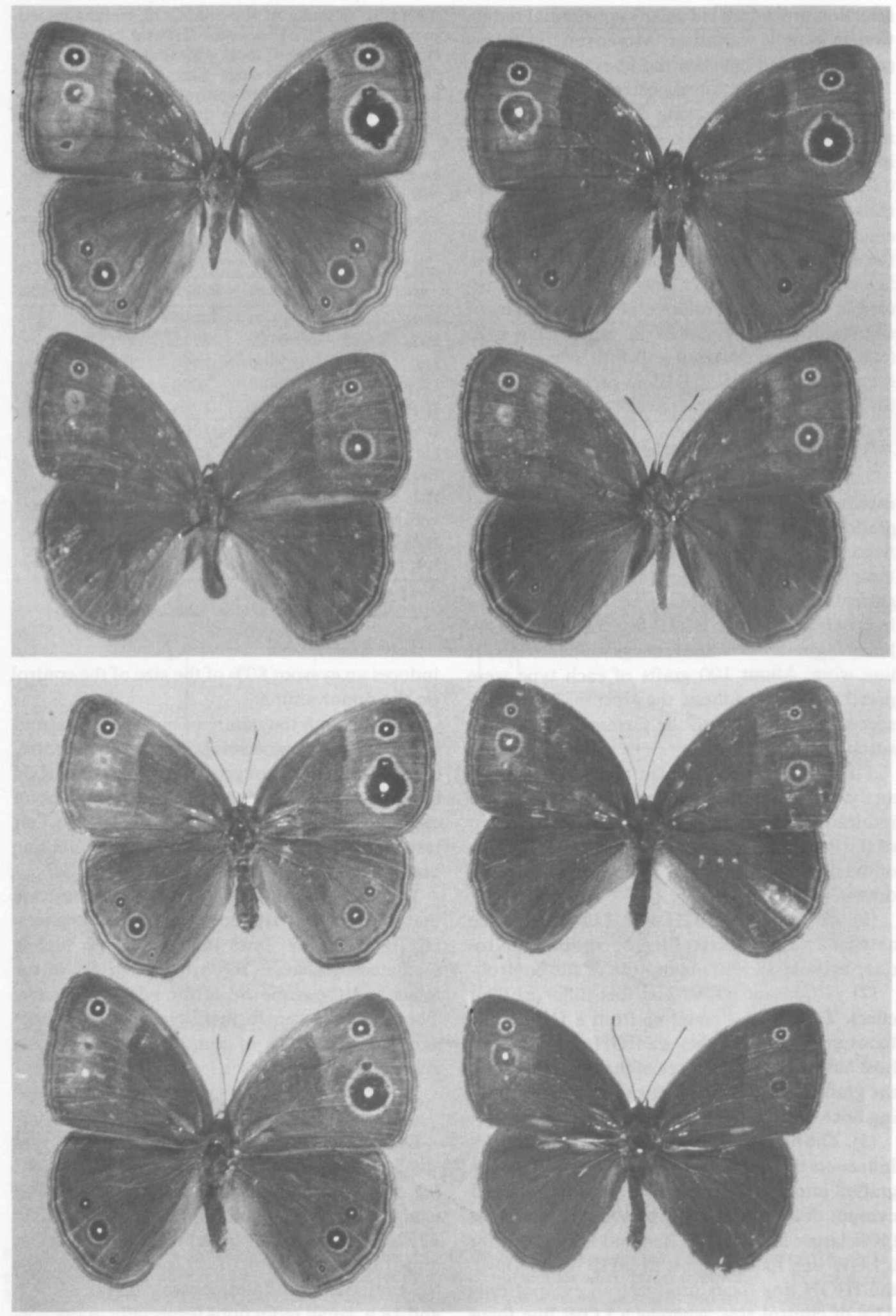


A)

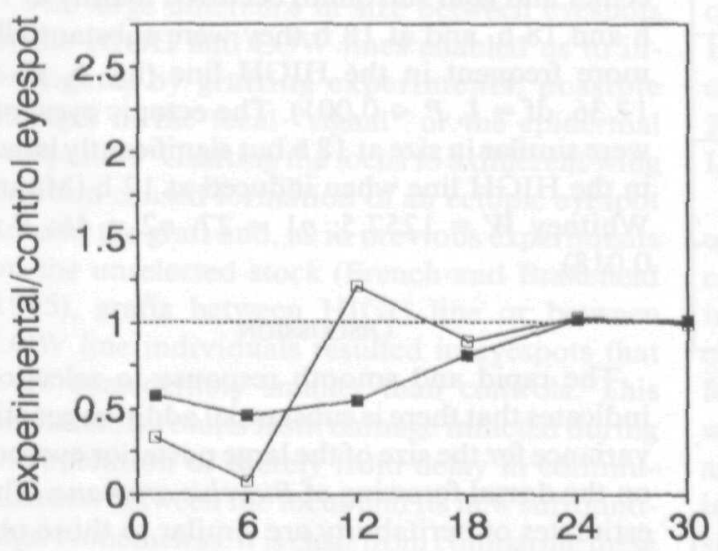

B)
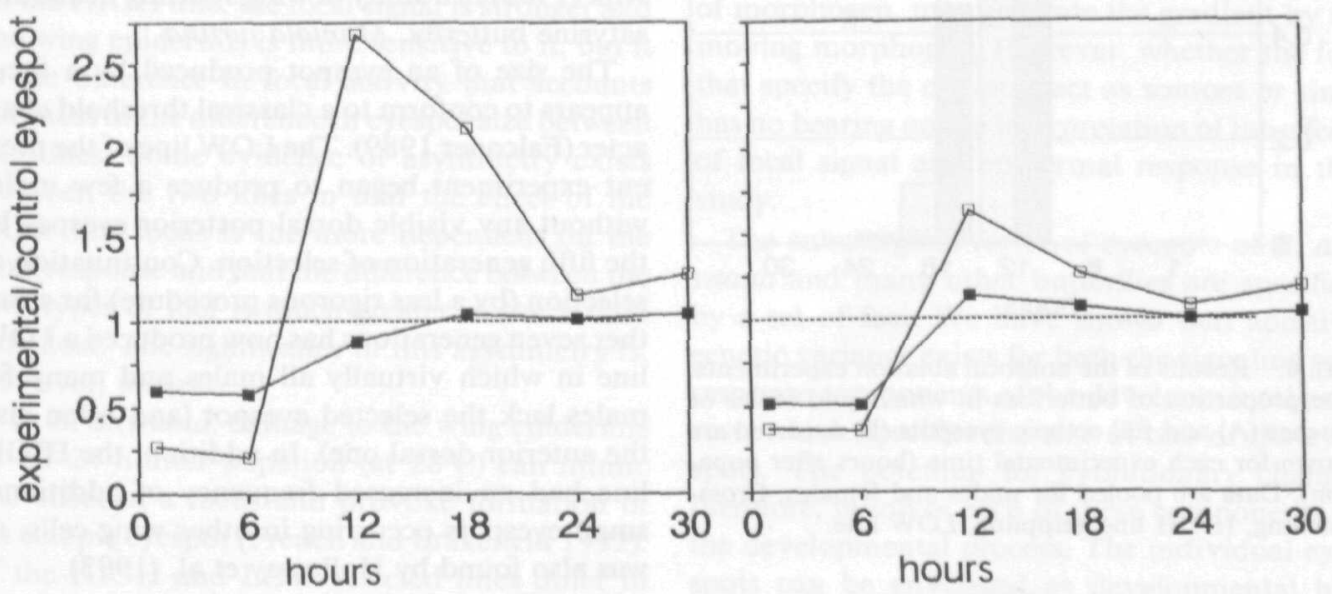

FIG. 5. Results of the focal ablation experiments in each sex on the posterior eyespot (A) and on the anterior eyespot (B). The mean value of the ratio of the area of the experimental eyespot relative to that of its control is shown for each experimental time (hours after pupation). $\mathbf{E}$, HIGH line; $\square$, LOW line. Note that $95 \%$ of untreated butterflies have left:right wing eyespot area ratios between 0.85 and 1.15 (French and Brakefield 1992).

FIG. 4. Photographs illustrating the results of grafting experiments performed on the foci of the selected eyespot in butterflies of the HIGH and LOW selected lines. Each row shows an example of the results of a reciprocal graft made in the early pupae: row 1 (top) is between two HIGH individuals; row 2, LOW to LOW; rows 3 and 4, HIGH to LOW (left to right). The central area (focus) of the large posterior eyespot on the left forewing of each butterfly was grafted to the same position in the center of the adjacent anterior wing cell on the left forewing of the other specimen in the same row. The posterior eyespots of the right forewings serve as unmanipulated controls. Note the larger size of the induced eyespots in row 1 relative to those in row 2, and of those from HIGH line donors relative to the LOW line donors in the bottom two rows. All butterflies are females except that in the lower right corner. The length of each forewing is about $2 \mathrm{~cm}$. 

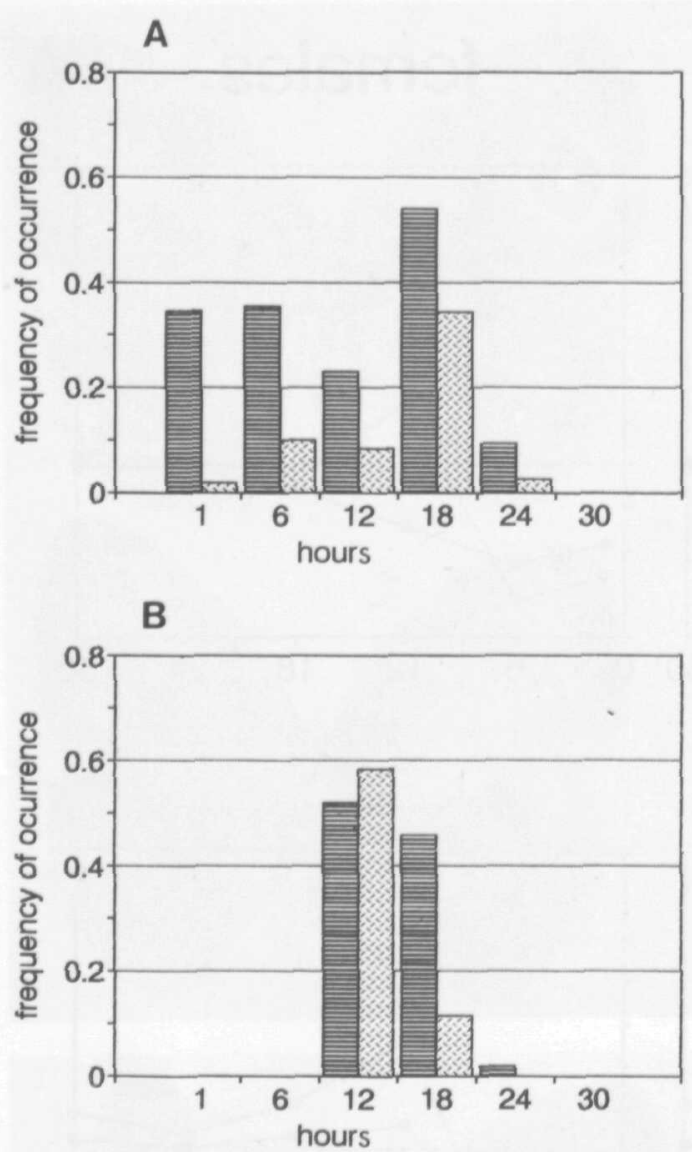

Fig. 6. Results of the nonfocal ablation experiments. The proportion of butterflies in which gold scales or patches (A) and full ectopic eyespots (B) occurred are shown for each experimental time (hours after pupation). Data are pooled for males and females. Crosshatching, HIGH line, stippling, LOW line.

terior eyespot of the HIGH line) or increases (especially in the anterior eyespot of the LOW line) occurred. Operations at $24 \mathrm{~h}$ or $30 \mathrm{~h}$ produced very little or no effect on eyespot size. The apparent differences between eyespots and between lines in the $12 \mathrm{~h}$ and $18 \mathrm{~h}$ response are probably related to the effect of damage in mimicking focal activity and will be considered in the Discussion.

\section{Nonfocal Damage and the Induction of Ectopic Pattern}

Damage at the nonfocal site produced ectopic patterns similar to those obtained on the unselected stock (French and Brakefield 1992). Scattered gold scales and gold patches occurred at low frequency following injury at 1-24 h (fig. 6).
The frequency was, however, significantly higher in the HIGH line ( $\chi^{2}$ tests, $P<0.05$ ), except at $24 \mathrm{~h}$. Full ectopic eyespots (involving a black center and gold surround) occurred mainly at 12 $\mathrm{h}$ and $18 \mathrm{~h}$, and at $18 \mathrm{~h}$ they were substantially more frequent in the HIGH line (fig. $6, \chi^{2}=$ $17.36, \mathrm{df}=1, P<0.001$ ). The ectopic eyespots were similar in size at $18 \mathrm{~h}$ but significantly larger in the HIGH line when induced at $12 \mathrm{~h}$ (MannWhitney $W=1257.5 ; n 1=27, n 2=46 ; P=$ $0.018)$.

\section{Discussion}

The rapid and smooth response to selection indicates that there is substantial additive genetic variance for the size of the large posterior eyespot on the dorsal forewing of Bicyclus anynana. The estimates of heritability are similar to those obtained by Holloway et al. (1992) from a selection experiment on the small anterior ventral eyespot of $B$. anynana and by Brakefield and van Noordwijk (1985) in a study of wing spotting in another satyrine butterfly, Maniola jurtina.

The size of an eyespot produced by a focus appears to conform to a classical threshold character (Falconer 1989). The LOW line of the present experiment began to produce a few males without any visible dorsal posterior eyespot by the fifth generation of selection. Continuation of selection (by a less rigorous procedure) for a further seven generations has now produced a LOW line in which virtually all males and many females lack the selected eyespot (and often also the anterior dorsal one). In addition, the HIGH line had an increased frequency of additional small eyespots occurring in other wing cells, as was also found by Holloway et al. (1993).

The effects of selection on wing pattern demonstrate positive genetic correlations between the selected posterior dorsal eyespot and the other measured eyespots on both surfaces of the forewing and of the hindwing (see also Holloway et al. 1993). A simple and plausible model of the development of an eyespot involves the production of an unstable morphogen by the predetermined cells of the focus, its diffusion to form a radial concentration gradient, and the response of the epidermis leading to concentric rings of differing scale cell pigmentation (Nijhout 1980, 1991; French and Brakefield 1992). It is likely that all eyespot patterns on the butterfly form by the same basic developmental mechanism (Nijhout 1991). In this case, allelic combinations favored by selection for their effect on the size 
of one eyespot (through the morphogen gradient or the response to it) would be expected to have a similar effect on the other pattern elements.

The large difference in size between eyespots of the HIGH and LOW lines enabled us to investigate, by grafting experiments, possible changes in the focal "signal" or the epidermal "response." Grafting the focus to a different wing position caused formation of an ectopic eyespot around the graft and, as in previous experiments on the unselected stock (French and Brakefield 1995), grafts between HIGH line or between LOW line individuals resulted in eyespots that were considerably smaller than controls. This presumably results from damage inflicted during the operation or merely from delay in communication between the focus and its new surroundings. Nonetheless, it is clear from comparing these results with those of grafting a focus from one line onto a host from the other line, that these lines differ in both signal and response (table 1). In the HIGH line, the focal signal is stronger and the wing epidermis is more sensitive to it, but it is the difference in focal activity that accounts for most of the difference in eyespot size between the lines. Some evidence of asymmetry exists between the two lines in that the effect of the LOW line focus is the more dependent on the host response and that the difference between the two types of foci is much greater in the $\mathrm{HIGH}$ line host. The significance of this asymmetry is, however, unclear.

In $B$. anynana, damage to the wing epidermis at $12-24 \mathrm{~h}$ after pupation (at $28^{\circ} \mathrm{C}$ ) can mimic the effect of a focus and provoke formation of an ectopic eyespot (French and Brakefield 1992). If the HIGH and LOW selected lines differ in response to a focal signal, they might be expected to differ in response to nonfocal ablation. The results of the experiments showed only small differences between the lines, but they did indeed indicate an increase in size or frequency of ectopics in the HIGH line.

Focal injury soon after pupation removes or diminishes the eyespot, and this effect is clearly seen in both lines and in both the anterior and posterior eyespots (fig. 5). In the unselected stock, however, later damage increases the size of the small anterior, but not the large posterior, eyespot (French and Brakefield 1992). The difference between eyespots was attributed to the transient damage effect overriding the loss of the weak anterior focus (giving an enlargement of pattern) but not of a strong posterior focus. A difference in focal strength between the selected lines would similarly explain their difference in response to focal injury at 12-18 h (see fig. 5). Hence, increases occur to the small anterior eyespot in the HIGH line and especially in the LOW line. Decreases occur to the large posterior eyespot of the HIGH line, but increases frequently occur in the LOW line where the focal signal is weaker.

In terms of a gradient mechanism, the "strength of the focal signal" could correspond to an increase in the amount of morphogen produced (or in its stability or its diffusion coefficient) or to a change in timing; a larger eyespot could result if focal activity started earlier or gradient levels were interpreted later in development. Our damage experiments give no evidence for a change in timing, but neither do they exclude the possibility that such variation contributes to the difference in eyespot phenotype between the lines.

French and Brakefield (1992) suggest that the foci in $B$. anynana, rather than acting as sources of morphogen, may generate the gradient by removing morphogen. However, whether the foci that specify the eyespots act as sources or sinks has no bearing on the interpretation of the effects of focal signal and epidermal response in this study.

The submarginal series of eyespots of $B$. anynana and many other butterflies are specified by a set of foci. We have shown that additive genetic variance exists for both the signaling and response components of the developmental process, which specifies the size of one of the eyespots. The potential for evolutionary change, therefore, involves each of these components of the developmental process. The individual eyespots can be envisaged as developmental homologues. Thus, the complex trait of the eyespot pattern involves a set of interrelated quantitative characters. Both developmental and functional interrelationships among characters will influence the structure of the phenotypic and genetic covariation. Previous studies on other species of butterfly have demonstrated positive phenotypic correlations among eyespots (see Brakefield 1984; Nijhout 1991). This study and that of Holloway et al. (1993) show that pleiotropic effects of genes on the phenotypic characters (the eyespots) that share common developmental pathways leads to genetic covariation among the characters. Kingsolver and Wiernasz (1991a) have made similar inferences for the wing pattern of melanized patches in the butterfly Pieris occidentalis but without any direct data about developmental 
pathways. In a study of head and thorax traits in Drosophila melanogaster, Cowley and Atchley (1990) found that the pattern of phenotypic and genetic covariation indicated that characters derived from the same imaginal disc are more highly correlated than those derived from different discs.

The phenotypic plasticity in Bicyclus species is associated with more or less general changes in eyespot size on the ventral wing surfaces (see Condamin 1973). The hypothesis about the adaptive significance of this plasticity (Brakefield and Larsen 1984; Brakefield 1987b; Brakefield and Reitsma 1991) predicts that selection for crypsis in the dry season will favor a general reduction in ventral eyespots, whereas deflective functions in the wet season will favor the opposite. Such functional interrelationships would complement the developmental organization as predicted by Cheverud (1984). The functional significance of the dorsal eyespots is unclear although they may sometimes function as deflective devices in both seasons in association with the rapid partial opening and closing of the wings ("wing flicking"), which may occur shortly after butterflies alight (N. Reitsma pers. comm. 1993). Kingsolver and Wiernasz's (1991a, 1991b) studies clearly demonstrate the role of functional interrelationships associated with thermoregulatory behavior in shaping the covariation of the elements of the wing pattern melanization in Pieris butterflies.

The characteristic pattern of relative size of the eyespots in B. anynana is presumably a property of the earlier determination of the foci themselves. This study and that of Holloway et al. (1993) show that it may be difficult to achieve a response to selection for changes in these characteristics; in other words, to change an individual eyespot, or a subset thereof, whereas other eyespots remain unchanged or change in the opposite direction. Single genes producing a localized and discrete shift in phenotype may provide the basis of much of this type of change as can be observed in differences across species of $\mathrm{Bi}$ cyclus (Brakefield and French 1993). Future experiments will also investigate the developmental and genetical basis of additional features of eyespots such as their shape, position, and pigment composition.

\section{ACKNOWLEDGMENTS}

We thank E. Schlatmann and her colleagues for growing maize for hungry larvae and G. Hol- loway, J. Roskam, and J. Windig for their comments on the manuscript.

\section{LITERATURE CITED}

Bowers, M. D., I. L. Brown, and D. Wheye. 1985 Bird predation as a selective agent in a butterfly population. Evolution 39:93-105.

Brakefield, P. M. 1984. The ecological genetics of quantitative characters in Maniola jurtina and other butterflies. Pp. 167-190 in R. I. Vane-Wright and P. R. Ackery, eds. The biology of butterflies. Academic Press, London.

- 1987a. Industrial melanism: Do we have the answers? Trends in Ecology and Evolution 2:117122.

1987b. Tropical dry and wet season polyphenism in the butterfly Melanitis leda (Satyridae): Phenotypic plasticity and climatic correlates. Biological Journal of the Linnean Society 31:175-191.

Brakefield,P.M., and V. French. 1993. Butterfly wing patterns: developmental mechanisms and evolutionary change. Acta Biotheoretica 41:447-468.

1995. Eyespot development on butterfly wings: the epidermal response to damage. Developmental Biology. In press.

Brakefield, P. M., and T. B. Larsen. 1984. The evolutionary significance of dry and wet season forms in some tropical butterflies. Biological Journal of the Linnean Society 22:1-12.

Brakefield, P. M., and A. J. van Noordwijk. 1985. The genetics of spot pattern characters in the meadow brown butterfly Maniola jurtina (Lepidoptera: Satyridae). Heredity 54:275-284.

Brakefield, P. M., and N. Reitsma. 1991. Phenotypic plasticity, seasonal climate and the population biology of Bicyclus butterflies (Satyridae) in Malawi. Ecological Entomology 16:291-303.

Cheverud, J. M. 1984. Quantitative genetics and developmental constraints on evolution by selection. Journal of Theoretical Biology 110:155-171.

Condamin, M. 1973. Monographie du genre Bicyclus (Lepidoptera, Satyridae). Memoires de l'Institut Fondamental d'Afrique Noire, IFAN, Dakar.

Cowley, D. E., and W. R. Atchley. 1990. Development and quantitative genetics of correlation structure among body parts of Drosophila melanogaster. American Naturalist 135:242-268.

Falconer, D. S. 1989. Introduction to quantitative genetics, 3d ed. Longman, London.

French, V., and P. M. Brakefield. 1992. The development of eyespot patterns on butterfly wings: morphogen sources or sinks? Development 116:103109.

1995. Eyespot development on butterfly wings: the focal signal. Developmental Biology. In press.

Holloway, G. J., P. M. Brakefield, and S. Kofman. 1993. The genetics of wing pattern elements in the polyphenic butterfly, Bicyclus anynana. Heredity 70:179-186.

Kingsolver, J. G., and D. C. Wiernasz. 1991a. Development, function, and the quantitative genetics of wing pattern melanin in Pieris butterflies. Evolution 45:1480-1492. 
1991b. Seasonal polyphenism in wing-pattern and thermoregulatory adaptation in Pieris butterflies. American Naturalist 137:816-830.

Koch, P. B. 1992. Seasonal polyphenism in butterflies: A hormonally controlled phenomenon of pattern formation. Zoologische Jahrbucker Abteilung für Allegmeine Zoologie und Physiologie der Tier. 96:227-240.

Mallet, J., and N. Barton. 1989. Strong natural selection in a warning-color hybrid zone. Evolution 43:421-431.

Nijhout, H. F. 1980. Pattern formation on Lepidopteran wings: determination of an eyespot. Developmental Biology 80:267-274.

1990. A comprehensive model for colour pattern formation in butterflies. Proceedings of the Royal Society of London Series B 239:81-113.

1991. The development and evolution of butterfly wing patterns. Smithsonian Institution Press, Washington, D.C.

Scharloo, W. 1987. Constraints in selection response. Pp. 125-149 in V. Loeschcke, ed. Genetic constraints on adaptive evolution. Springer, Berlin.

- 1990. The effect of developmental constraints on selection response. Pp. 197-210 in G.
Vida and J. Maynard Smith, eds. Organisational constraints on the dynamics of evolution. Manchester University, Manchester.

Schwanwitsch, B. N. 1924. On the groundplan of wing-pattern in nymphalids and certain other families of rhopalocerous Lepidoptera. Proceedings of the Royal Society of London Series B 34:509-528.

Turner, J. R. G. 1984. Mimicry: the palatability spectrum and its consequences. Pp. 141-161 in R. I. Vane-Wright and P. R. Ackery, eds. The biology of butterflies, Academic Press, London.

Watt, W. B., C. Kremen, and P. Carter. 1989. Testing the "mimicry" explanation for the Colias "alba" polymorphism: patterns of cooccurrence of Colias and Pierine butterflies. Functional Ecology 3:193199.

Windig, J. J. 1992. Seasonal polyphenism in Bicyclus safiza: a continuous reaction norm. Netherlands Journal of Zoology 42:583-594.

1994. Reaction norms and the genetic basis of phenotypic plasticity in wing pattern of the butterfly Bicyclus anynana. Journal of Evolutionary Biology. In press.

Corresponding Editor: J. Hanken 